\title{
Carriage of antibiotic-resistant pneumococci in a cohort of a daycare center
}

\author{
Demóstenes Gómez-Barreto, MC, (1) Ernesto Calderón-Jaimes, MC, MSP, ${ }^{(1)}$ Romeo S Rodríguez, MC, ${ }_{1}^{(1)}$ \\ Luz Elena Espinosa, Q BP, D ra en C, ${ }^{(1)}$ LucíaViña-Flores, MC, ${ }^{(1)}$ Verónica Jiménez-Rojas, Q BP. ${ }^{(1)}$
}

\begin{abstract}
Gómez-Barreto D, Calderón-Jaimes E, Rodríguez RS, Espinosa LE,Viña-Flores L, Jiménez-RojasV. Carriage of antibiotic-resistant pneumococci in a cohort of a daycare center. Salud Publica Mex 2002;44:26-32.

The English version of this paper is available too at: http://www.insp.mx/salud/index.html
\end{abstract}

\begin{abstract}
A bstract
Objective. To define epidemiologic relationships to determine the prevalence and potential risk factors for nasopharyngeal colonization by antibiotic-resistant pneumococci, their serotypes and their antibiotic susceptibility patterns in children attending a daycare center (DCC). Material and MethodsA prospective cohort study was conducted among children $(n=53)$ attending the DCC at Hospital Infantil de México Federico Gómez, which is staffed by 20 employees. Patients were enrolled in the study during a two-year period from September 1997 to September 1999.All the participants were followed prospectively, swabbing them every four months.The strains recovered were typed and screened for susceptibility to several antibiotics.The daycare records were reviewed also. 0 dds ratios and fisher's exact test: or chi square test of significance were computed from contingency tables as appropriate. Exact $95 \%$ confidence intervals were computed for odds ratios. Data analysis was performed using Epi statistics program version $6.04 \mathrm{a}$. Results. Pneumo cocci were recovered from 45/53 of the infants at one or more visits. A total of 178 isolates were carried.T he carriage rate was $47 \%$. 0 nly 7 adults acquired pneumococci during the study.Types 6,14,19 and 23 were prevalent and represented $77 \%$ of the total. Antibioticresistant strains were higher to penicillin and erythromycin. Conclusions. Children were frequent carriers of pneumococci, the rate of carriage was high in infancy and tended to decrease with age. The types commonly carried by children were the same as those causing invasive disease. There is a high proportion of carriers with antibiotic-resistant S. pneumoniae strains. Children who have had frequent antimicrobial courses are at particular risk.The English
\end{abstract}

\author{
Gómez-Barreto D, Calderón-Jaimes E, Rodríguez RS, \\ Espinosa LE,Viña-Flores L, Jiménez-RojasV. \\ Portadores nasofaríngeos de neumococo antibiótico-resistente \\ en niños asistentes a guardería. \\ Salud Publica Mex 2002;44:26-32. \\ El texto completo en inglés de este artículo también \\ está disponible en: http://www.insp.mx/salud/index.html
}

\section{Resumen}

Objetivo. Analizar longitudinalmente la dinámica de colonización por Streptococcus pneumoniae, determinar la prevalencia, los factores de riesgo potencial para la colonización nasofaríngea con cepas de neumococo resistentes, determinar los serotipos y el perfil de sensibilidad a varios fármacos antimicrobianos. Material y métodos. Estudio prospectivo de una cohorte de niños de guardería, hecho de septiembre de 1997 a septiembre de 1999 entre 53 niños asistentes a la guardería del Hospital Infantil de México Federico Gómez, atendida por 20 empleados.Todos los participantes fueron seguidos en forma prospectiva, to mándose exudado nasofaríngeo cada cuatro meses. Los S. pneumoniae aislados se tipificaron y sometieron a pruebas de sensibilidad a diversos fármacos. Las razones de momios y la prueba exacta de Fisher 0 ji cuadrada se efectuaron a través de tablas de contingencia; se utilizaron intervalos de confianza a 95\% para las razones de momios. Para el análisis se empleó el programa estadístico EPI IN FO, versión 6.04 a. Resultados. S. pneumoniae se recuperó de 45/53 niños en una o más de las to mas. Se aisló un total de 178 cepas. El promedio de portador fue de $47 \%$. Sólo siete adultos adquirieron un neumo co co durante el estudio. Los tipos 6, 14, 19 y 23 representaron $77 \%$ del total. Se encontró elevada resistencia a la penicilina y eritromicina. Conclusiones. El estado de portador nasofaríngeo de S. pneumoniae, es un proceso dinámico. La colonización ocurre durante los primeros meses de vida y comprende solamente unos cuantos serotipos de neumococo. El estado portador disminuye conforme avanza la edad. Se encontró alta proporción de portadores con cepas resistentes de neumo coco. Los niños que recibieron varios cursos de antimicrobianos, fueron

(1) Hospital Infantil de México Federico Gómez. México, D.F., México.

Received on: January 8,2001 - Accepted on: 0 ctober 3, 2001

Address reprint requests to: D. Gómez Barreto. Departamento de Infectología, Hospital Infantil de México Federico Gómez, calle Dr. Márquez 162, Colonia D octores, 06729 México, D.F., México.

Correo electrónico: dgbarreto30@ yahoo.com.mx 
version of this paper is available too at: http://www.insp.mx/ salud/index.html

Key words: naso pharyngeal carriage; Streptococcus pneumoniae; drug resistance,microbial; child day care centers; Mexico los que mostraron mayor riesgo de presentar estado portador. El texto completo en inglés de este artículo también está disponible en: http://www.insp.mx/salud/index.html

Palabras clave: po rtador meso faríngeo;Streptococcus pneumoniae; resistencia microbiana a las drogas; jardines infantiles; México
$S$ treptococcus pneumoniae is a leading cause of a variety of diseases including otitis media, bacteremia, pneumonia, meningitis, and other infections among children, individuals with debilitating medical conditions, and the elderly. ${ }^{1-7}$ It is also found as part of the normal nasopharyngeal flora in about 10 to $50 \%$ of healthy children, with particularly high rates in those attending daycare centers (DCC). ${ }^{8}$

Treatment of most infections remains empirical due to the lack of suitable diagnostic specimens in cases of sinusitis, otitis, and pneumonia. ${ }^{4-6}$ Current treatment regimens are based mainly on historical data and on findings in studies of patients infected with fully susceptible strains. However, the emergence of antibiotic-resistant strains of S. Pneumoniae complicates the empirical management of infections.

Increased nasopharyngeal carriage of antibioticresistant pneumococci strains has been documented in children attending DCC. ${ }^{9-21}$ Upper respiratory tract and invasive infections caused by such strains have increased. Antibiotic-resistant pneumococci were more common in isolates from children in DCC than in isolates from patients admitted at a tertiary care hospital -a group of patients presumably at increased risk of infection by resistant strains. ${ }^{12,13,20}$

This paper presents the results of the Institutional Surveillance System for Pneumococcal Infections during 1997-1999. The objectives of the present study were to determine the prevalence and potential risk factors for nasopharyngeal colonization with antibiotic-resistant pneumococci, and to describe its serotypes and its antibiotic susceptibility patterns.

\section{Material and Methods}

The study group consisted of children between 3 and 48 months of age, attending the DCC at Hospital Infantil de México Federico Gómez (Children's Hospital of Mexico). This DCC is staffed by 20 employees (defined as adults in the paper). Children were divided into three age subgroups in three rooms: infants from 3 to 17 months $(n=14)$; toddlers from 18 to 36 months $(n=16)$; and nursery children from 37 to 48 months $(\mathrm{n}=23)$.

Children stayed at the center an average of eight hours a day, five days a week, and around 45 weeks per year. Approximately $85 \%(45 / 53)$ of the children and $75 \%(15 / 20)$ of the adults were followed throughout the study. Every child who for any reason quit attending the DCC was replaced by another infant of the same age. Therefore, we selected for the study all 53 children ( 24 males and 29 females) and the 20 adult caretakers (all females, with a median age of 34 years) who were at the daycare center between September 1, 1997 and September 30, 1999.

Informed consent was obtained from parents whose children were enrolled in the study to provide routine medical care and to obtain nasopharyngeal specimens for culturing.

Date of birth, gender, and use of antibiotics in the previous 15-30 days were recorded for each child enrolled in the study. A research nurse reviewed the daycare records every day. Children who had taken antibiotics within two weeks prior to the culture were not included at the time of swabbing and were scheduled for later swabbing.

Investigation of risk factors, demographics, and medical history including antibiotic use, infections, and hospitalizations, were recorded during the study period. Medical records were reviewed to document infection events in study children. All information was collected without knowledge of the child's carrier state.

A carrier was defined as a person from whom a strain of $S$. pneumoniae was isolated by nasopharyngeal swab culture on one or more occasions during the study period. Acquisition of pneumococci was defined as the recovery of any pneumococcal type for the first time, or by the recovery of a type not previously isolated in a given child. Reacquisition of a previously carried type was defined by the identification of one or more cultures negative for that type, in the absence of antibiotic therapy at the time of culture, and an interval of more than three months before its reap- 
pearance. Duration of carriage was calculated from the date of acquisition to the date of the last consecutive culture positive for a given pneumococcal type.

Data on demographic characteristics and medical history, including antibiotic use, infections, and hospitalizations, were collected during the study period and records were reviewed to complete the documentation of infection events in children. All information was collected without knowledge of the child's carrier state.

Laboratory procedures. During the study period, all the S. pneumoniae strains isolated from nasopharyngeal swabs of enrolled children and adults were collected prospectively and stored frozen $\left(70^{\circ} \mathrm{C}\right)$.

\section{Specimen collection and identification of S. pneumoniae}

The first swab specimens from children and adults were taken in September 1997 and every 4 months thereafter until September 1999. All the samples were obtained by a single investigator who used a cotton swab placed 1 to 1.5 inches into the nasopharynx. Specimens were initially processed in the same laboratory within two hours after collection. Swabs were placed on nonselective $5 \%$ sheep blood-agar and incubated at $34-35^{\circ} \mathrm{C}$ in a 5 to $7 \% \mathrm{CO}_{2}$ atmosphere for 24 to 48 hours. Alphahemolytic colonies were evaluated by bacterial morphology, optochin disk susceptibility, Gram-stain smear, and bile solubility tests to identify S. pneumoniae. 22

The swelling test using omniserum pools and type/group-specific antisera were used (Statens Seruminstitute, Copenhagen, Denmark) for serotyping.

All strains were routinely screened for susceptibility to penicillin with a $1.0 \mathrm{mg}$ oxacillin disk (BBL Microbiology Systems, Mexico) using the Kirby-Bauer disk diffusion method. ${ }^{23}$ A zone of inhibition $\geq 20 \mathrm{~mm}$ indicated that the strain was susceptible, while those strains with a zone of inhibition $£ 19 \mathrm{~mm}$ were susceptible to penicillin. ${ }^{24}$

All antibiotics were supplied as laboratory powders of known potency and stocks were made as recommended by the manufacturer. The antimicrobials used were : penicillin G potassium, erythromycin, ceftriaxone, and vancomycin.

The Minimal Inhibitory Concentration (MIC) was determined by the broth microdilution method, in Mueller-Hinton broth (Difco, Mexico) supplemented with $10 \mathrm{mg}$ of $\mathrm{MgCl} / 1,20 \mathrm{mg}$ of $\mathrm{CaCl}_{2} / 1$ and $5 \%$ lysed equine red blood cells. The plates were visually read. These agents and their breakpoint concentrations $(\mathrm{mg} / \mathrm{mL})$, were classified as susceptible (S), intermediate (I), or resistant $(\mathrm{R})$ to each drug tested: Penicillin (S) $\leq 0.06$; (I) $0.12-1.0$; (R) $\geq 2.0$; erythromycin $(\mathrm{S}) \leq 0.25$; ( I ) 0.5 ; (R) $\geq 1.0$; ceftriaxone (S) $\leq 0.5$; (I) 1.0 ; (R) $\geq 2.0$, and vancomycin $(R) \geq 1.0$.

The results of susceptibility testing for these antimicrobials were defined according to the 1997 guidelines of the National Committee for Clinical Laboratory Standards (NCCLS). ${ }^{24}$

For statistical analysis odds ratios and Fisher's exact or chi square tests of significance were computed from contingency tables. Exact 95\% confidence intervals were computed for odds ratios. Data analysis was performed using the Epi Info statistics program (version 6.04a, CDC, Atlanta, GA. 1994.) ${ }^{25}$

\section{Results}

DCC isolates - A total of 53 children younger than 4 years and 20 DCC employees participated two-year during the two-year follow-up study.

The 53 children in this study were seen on a total of 378 occasions, an average of seven visits per child. Pneumococci were recovered from 45 of $53(85 \%)$ of the infants at one or more visits. A total of 178 pneumococcal isolates were found in carriers. Thus, the carriage rate based on the number of strains recovered for the total number of visits was $47 \%$. Pneumococci were recovered four times per child on average (three to five consecutive cultures). Children not cultured were either absent from the DCC or their parents refused to have their cultures taken.

All 53 infants acquired pneumococci during the study period: 25 acquired one type; 14, two types; 9 , three types; and 5, four types. These acquisitions accounted for 100 of the 178 pneumococcal strains that were carried in total. Acquisitions were documented in 368 of the 378 swabbing specimens.

\section{Isolates in adults}

There was a high level of work shif rotation among the 20 employees; 15 were followed for $\geq 6$ months, 10 for $\geq 12$ months and 7 for more than 18 months. Only seven of the adults acquired pneumococci during the study period; one of them with serotype 7 (June 1998); not all adult infections were related with strains from children at that time. Five pneumococcal strains were acquired in September 1998 and were related to those of children; two with type 19F and the other three with type $6 \mathrm{~B}, 10$, and 11 respectively. The last strain recovered in September 1999 was of type 3. 
Table I

Serotype distribution of Strains of S. PNEUMONIAE CarRied among 53 healthy CHILdREN less than 4 YEARS OF AGE. MÉXICO, 1997-1999

\begin{tabular}{lcc} 
Type/group & No. of isolations* $(\%)$ & No. of carriers \\
$19 \mathrm{~F}$ & $65(36.5)$ & 38 \\
\hline $6 \mathrm{~A}$ & $32(17.9)$ & 27 \\
\hline $6 \mathrm{~B}$ & $24(13.4)$ & 21 \\
\hline $23 \mathrm{~F}$ & $7(3.9)$ & 7 \\
\hline 14 & $6(3.3)$ & 6 \\
\hline $19 \mathrm{~A}$ & $6(3.3)$ & 6 \\
\hline 15 & $4(2.2)$ & 4 \\
\hline $9 \mathrm{~A}$ & $3(1.6)$ & 3 \\
\hline 16 & $3(1.6)$ & 3 \\
\hline 18 & $3(1.6)$ & 3 \\
\hline 8 & $2(1.1)$ & 2 \\
\hline $9 \mathrm{~V}$ & $2(1.1)$ & 2 \\
\hline 11 & $2(1.1)$ & 2 \\
\hline $19 \mathrm{~B}$ & $2(1.1)$ & 2 \\
\hline 42 & $2(1.1)$ & 5 \\
\hline N ot typable & $5(2.8)$ & 10 \\
\hline 0 thers & $10(5.6)$ & - \\
\hline Total & 178 & \\
$*$ Includes multiple types isolated & & \\
\hline $1,2,3,4,5,13,17,22,23 \mathrm{~A}, 31$ & & \\
\hline & & \\
\hline
\end{tabular}

\section{Distribution of carriage types}

Twenty-five pneumococcal serotypes were found among the 178 pneumococcal strains cultured; five strains were not typeable. Two different types were found simultaneously in 23 occasions; three in 9 occasions and four on 5 occasions.
Table I shows the serotype distribution of all strains carried; data are arranged to show the overall frequency of isolation, the number of infants who carried a given type on at least one occasion, and the mean number of visits at which these infants carried that given type. Types 19F (65), 6A (32), 6B (24), accounted for $68 \%$ of the strains. If we add types $23 \mathrm{~F}$, $19 \mathrm{~A}$, and 14 , the six types represented $77 \%$ of the total. The more frequent isolation of these six types was partially explained by their longer duration of carriage. Table II shows the distribution of serotypes, the number of children swabbed, and the number of strains recovered during the study period.

\section{A ge of acquisition}

The mean age at which infants acquired their first pneumococci was five months, with a range of two to seven months. Acquisition of a second strain occurred in 14 children, at four months on average after the first strain, around nine months of age. Strains of a third type in nine children were acquired three months after the last acquisition (at 12 months of age). Strains of a fourth type in five children were acquired at the age of eighteen months. The overall mean age for all 140 acquisitions of pneumococci was 8.4 months. There was a trend toward an increased risk for carriage with increasing age until 12 months of age, after which acquisition diminished.

\section{Reacquisition, persistence and antibiotic therapy}

According to our operational definitions, 27 such reacquisitions occurred in 22 of the 53 children. Reacquired

Table II

Distribution OF S. PNEUMONIAE ISOLATES FROM CHILDREN ATTENDING AT THE HOSPITAL INFANTIL DE MEXICO FEDERICO GOMEZ DAYCARE CENTER. MÉXICO, 1997-1999

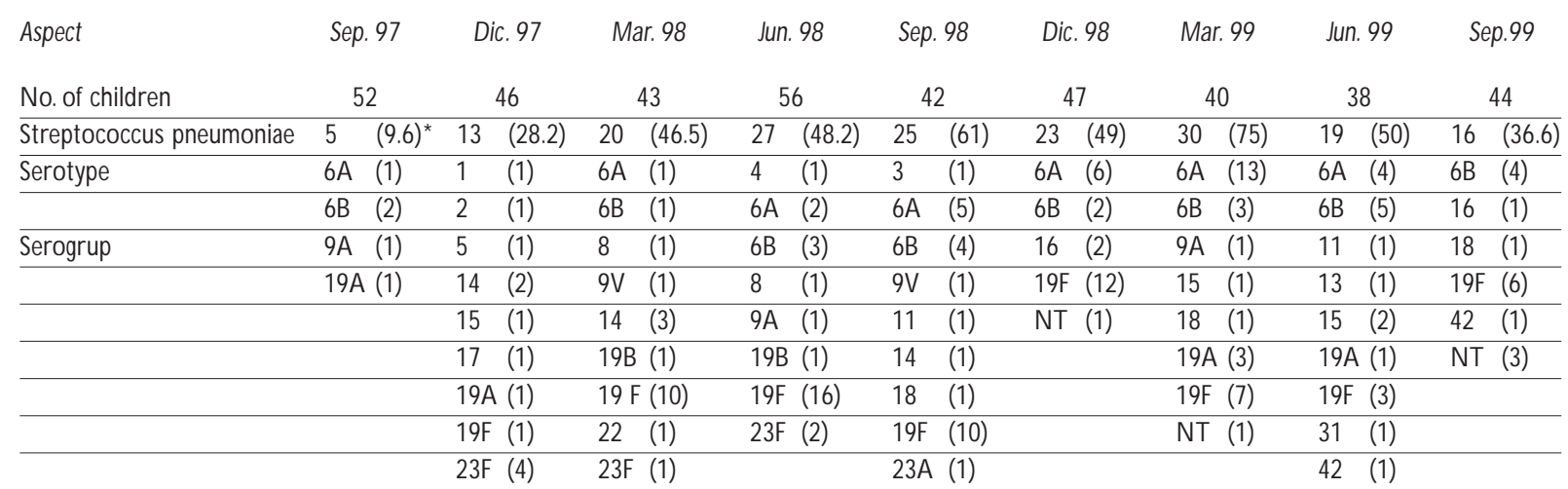

$*(\%)$ 
strains were predominantly ( $>80 \%$ ) the common types $19 \mathrm{~F}, 6 \mathrm{~A}, 6 \mathrm{~B}, 23 \mathrm{~F}$, and 14 . Eighteen out of 27 reacquisitions occurred after an intervening course of antibiotics. There were 79 courses (most of them in winter months), often with oral antimicrobial agents given to infants carrying pneumococci. Most of those children had upper respiratory infections (sinusitis, otitis media, pharyngitis, and common cold ). Carriers of the antibiotic-resistant strains were more likely than noncarriers to have received three or more courses of antimicrobial therapy in the preceding two months (18/27 carriers vs. $7 / 26$ non-carriers) (OR 6.98; $95 \%$ CI, 1.8-29 ). Unfortunately, both qualitative and quantitative antibiotic use was not assessed due to insufficient dosing and prescribing data in the medical records. All the antimicrobials were prescribed without knowledge of the presence of pneumococcal infection. Antibiotics commonly used for this purpose were amoxicillin, trimethoprim-sulfamethoxazole, and erythromycin.

No children at the DCC had pneumococcal bacteremia, pneumonia, or meningitis during the study period. Acute otitis media occurred in 10 of 18 persistent carriers (average 12 months) and in 6 of 32 noncarriers $(\mathrm{OR}=7 ; 95 \% \mathrm{CI}, 1.6-30)$. Most of the strains recovered from 14 to 18 of those carriers were nonsusceptible to penicillin, compared with 12 of 35 strains recovered in the first or second acquisition $(\mathrm{OR}=10,95 \%$ CI, 2.5-46; RR=3.0, 95\% CI, 1.8-5.0).

Persistence of the carrier strain in the upper respiratory tract was documented in 18 cases, including the same serotypes 19F, 6A, 6B, and 23F. Treatment for 13 of 18 persistent carriers failed to eradicate the carrier strain, mainly $19 \mathrm{~F}$.

\section{Duration of carriage}

A pneumococcal strain was recovered in one and to five consecutive swabbing events for a given child. Termination of carriage was recorded regardless of antibiotic therapy. The duration of carriage ranged from 3 to 12 months. In general, the younger the infant was at the time of acquisition, the longer a strain likely to be carried. Regardless of type, the first strain acquired was consistently carried longer than the second, third, or fourth strain. Again the groups 19F, 6A, $6 \mathrm{~B}$, and $23 \mathrm{~F}$, was carried significantly longer (mean 6.1 months versus 3.3 months, $p<0.01$ ) than other types. Of the four types carried for a longer period of time, $23 \mathrm{~F}$ was the least common and its average duration of carriage was the shortest (3 months).

In adults, according to the definition of acquisition and carriage, strains recovered at only one swabbing were assumed to have a carriage duration of four months.

\section{Seasonal pattern of pneumococcal acquisition and carriage}

Pneumococcal acquisition and carriage were related to both age of the infant and season of the year. The acquisition rate followed a seasonal pattern, with major peaks falling during the winter time (January through March of 1998 and 1999). The carriage rate was strongly age-related, increasing steadily with age during the first year. Carriage also fluctuated seasonally, with highest peaks in March, June, September, and December (Table II). There was no seasonal pattern of pneumococcal acquisition in adults.

\section{Antibiotic susceptibility patterns}

The susceptibility data to four antimicrobials tested against 178 isolates of S. pneumoniae are presented in Table III, with their individual numbers and percentages of susceptibility stratified by penicillin susceptibility. Twenty of 178 strains (11\%) were resistant to the four antimicrobials tested and were classified as multiresistant strains. From the seven strains recovered from adults, four were susceptible to all antimicrobials (types 3,7,10, and 11), and the other three (2 types $19 \mathrm{~F}$, and one $6 \mathrm{~B}$ ) were multiresistant.

Table III

SUSCEPTIBILITY* TO ANTIBIOTICS IN 178 STRAINS of Streptococcus PNEUMONIAE ISOLATED IN A DAYCARE CENTER. MÉXICO, 1997-1999

Drug and mic (mg/ml) No. (\%) of strains

Pnicillin

\begin{tabular}{ll}
$S \leq 0.06$ & $91(51)$ \\
\hline $\mathrm{I} 0.12-1.0$ & $68(38)$ \\
\hline$R \geq 2.0$ & $19(11)$
\end{tabular}

Erythromycin

\begin{tabular}{lr}
$S \leq 0.25$ & $102(57)$ \\
\hline$I 0.5$ & $43(24)$ \\
\hline$R \geq 1.0$ & $33(19)$
\end{tabular}

Ceftriaxone

\begin{tabular}{lrr}
$S \leq 0.5$ & 158 & $(88)$ \\
\hline $\mathrm{I} 1.0$ & 14 & $(8)$ \\
$\mathrm{R} \geq 2.0$ & 6 & $(4)$
\end{tabular}

Vancomycin

$R \geq 1.0$

0

References 23,24

salud pública de méxico / vol.44, no.1, enero-febrero de 2002 


\section{Discussion}

This study prospectively surveyed the nasopharyngeal colonization of children attending a single DCC. Very high rates of carriage of penicillin-resistant Streptococcus pneumoniae are documented. Our findings supports earlier studies from similar centers over the last decade. ${ }^{9-21}$ Recent research established daycare attendance as an important factor influencing the epidemiology of many infectious diseases. ${ }^{26-28}$ A number of studies have demonstrated a strong association between daycare attendance and increased carriage of $S$. pneumoniae, especially of resistant strains. ${ }^{13,28,29}$ Study findings demonstrated that daycare attendance and patterns of antibiotic use may be important factors influencing the epidemiology of antibiotic-resistant bacteria.

Every child in the study acquired a pneumococcus strain. Carriage occurred in $47 \%$ of children cultured. We found that the carriage rate increased with age, reflecting an increase in the number of types acquired. At baseline, it was observed that group 6 (A and $\mathrm{B}$ ) was prevalent as an endemic strain, and remained as a clone thereafter. Type $19 \mathrm{~F}$ appeared in the second culture and increased to become the dominant strain (Table II). Type 14 and groups 6,19, and 23, showed a disproportionately high incidence among children under four years of age. Persistent carriage was more frequent with these types. On the other hand, persistent nasopharyngeal carriage of single strains was serotype-dependent ${ }^{6,14,19,23}$ and occurred more commonly between 5 and 8 months of age. The duration of carriage decreased with the carriage of successive pneumococcal serotypes and hence was inversely correlated with age. A previously carried type was isolated simultaneously with a new type acquired. The very low carriage rate of $S$. pneumoniae in daycare center personnel, suggests that these adults are less susceptible or had a lower rate of exposure to pneumococci than the children attending the DCC. The lower colonizing rate and the shorter duration of carriage in the adults studied, may be correlated with the prevalence of serum antibodies to the colonizing types of pneumococci, whereas children had low or undetectable levels of these antibodies. ${ }^{27,28}$

The rate of carriage of penicillin-nonsusceptible S. pneumoniae strains isolated from the nasopharynx of children in the DCC studied, was extraordinarily high $(49 \%)$ in the study children. Our findings are less impressive than ones reported by Chiou and cols. ${ }^{30} \mathrm{Our}$ results also confirm the decreased susceptibility of antibiotic-nonsusceptible strains of pneumococci to other $\beta$-lactam drugs, on the other hand the resistence of these strains to erythromycin was $43 \%$.

High prevalence rates of antibiotic-resistant pneumococcal strains in children in the community are of concern, because epidemiologic studies suggest that a high prevalence of antibiotic-resistant isolates in the community results in increased clinical disease due to these resistant organisms. ${ }^{30}$ Thus, prevalence of antibiotic-nonsusceptible pneumococci continued to be high and was significantly higher in daycare centers, where resistant strains may become endemic and difficult to eradicate, as was the case for types 6,14,19, and 23.

Close contact among members of the group in a daycare center increases the probability that resistant organisms will spread among the attendees. ${ }^{28,29}$ Thus, the frequent use of antimicrobial agents to treat upper respiratory infections, a common illness in children in daycare centers, and the close contact of large numbers of young children that commonly occurs in daycare settings, could facilitate the emergence of antibiotic-resistant bacteria. In our study, most of the courses of antibiotics for these children (68/79) were prescribed during the winter time (December-January). On the other hand, 7 of 18 children with recurrent acute otitis media were shown to have persistent carriage of pneumococci (longer than 18 months), as has been reported in other studies. ${ }^{31,32}$

Extensive use of antibiotics to treat respiratory infections in children in daycare centers, may promote selection of antibiotic-resistant microorganisms. The special epidemiological characteristics of the daycare center environment could permit the spread of resistant strains that have been either selected or introduced in this setting. Children who acquire these organisms in DCC may subsequently spread them to susceptible hosts in the general community. The presence of multiply-resistant pneumococcal strains among children at a DCC and in household members and members of the surrounding community is of substantial importance because of the potential of these strains to cause invasive disease. . $^{6,-16}$

This study also demonstrates that the risk of carrying multiply-resistant strains of pneumococci is directly related to the administration of antimicrobial therapy in the preceding three to four months. In settings in which a strain is resistant to multiple antimicrobial agents, prevalent antibiotic therapy can result in increased risk of carriage of the drug-resistant strain.

The resistant strains isolated in this study are responsible for the majority of serious pneumococcal diseases in children attending our hospital, who acquired the infection in the community. The characteristics of 
carriage isolates could serve as an indicator of the prevalence of resistant strains in the community.

Future interventions for reducing the high prevalence of pneumococcal carriage in young children, particularly in those attending daycare centers should include the active immunization against $\mathrm{S}$. pneumoniae. Large studies have shown that a pneumococcal conjugate vaccine is immunogenic and reduces invasive disease in infants and children. ${ }^{33-35}$

\section{References}

1. Campbell GD, Silberman R. D rug-resistant Streptococcus pneumoniae. Clin Infect Dis 1998;26:1188.

2. Doern GV, Pfaller MA, Kugler K, Freeman J, Jones RN. Prevalence of antimicrobial resistance among respiratory tract iso lates of Streptococcus pneumoniae in N orth America: 1997 results from the SEN TRY Antimicrobial Surveillance Program. C lin Infect D is 1998;27:764.

3.Appelbaum PC .Antimicrobial resistance in Streptococcus pneumoniae. Clin Infect D is 1992;15:77.

4. Klugman KP. Pneumococcal resistant antibiotics. Clin Microbiol Rev 1990;3:171.

5. Jacobs MR. Treatment and diagnosis of infections caused by drug-resistant Streptococcus pneumoniae. Clin Infect D is 1992;15:119.

6. A ppelbaum PC, G ladkova C, H ryniewiez W, Kojouharov B, Kotulova D, Mijalcu $F$ et al. $C$ arriage of antibiotic-resistant Streptococcus pneumoniae by children in Eastern and Central Europe.A multicenter study with use of standardized methods. C lin Infect D is 1996;23:712.

7.C alderón JE. La resistencia antimicrobiana del Strepto coccus pneumoniae como un problema de salud pública. Salud Publica Mex 1999;41:360-361. 8. Pérez L, Liñarez J, Bosch J, López de Goicoechea MJ, Martín R.Antibiotic resistance of Streptococcus pneumoniae in childhood carriers. J Antimicrob Chemother 1987;19:278.

9. Gray BM, Converse GM, Dillon HC. Epidemiologic studies of Streptococcus pneumoniae in infants: Acquisition, carriage, and infection during the first 24 months of life.J Infect D is 1980;142:923.

10.Anderson KC, Maurer MJ, D ajani A S. Pneumococci relatively resistant to penicillin:A prevalence survey in children.J Pediatr 1980;97:939.

11. Radetsky MS, Istre GR, Johansen TL,Parmelee SW, Lauer BA,W iesenthal

AM et al. Multiply resistant pneumococcus causing meningitis: Its epidemiology within a daycare center. Lancet 1981;2:771.

12. Klugman KP, Koornhof HJ,W asas A, Storey K, G ilbertson I. Carriage of penicillin-resistant pneumococci.Arch D is Child 1986;61:377.

13. Henderson FW, G illigan PH, W ait K, G off DA. N aso pharyngeal carriage of antibiotic-resistant pneumococci by children in group day care.J Infect Dis 1988;157:256-263.

14. Rauch AM, 0 \$Ryan M, Van R, Pickering LK. Invasive disease due to multiple resistant Streptococcus pneumoniae in a Houston, Tex, D ay $C$ are Center.AJDC 1990;144:923.

15. D oyle MG, Morrow AL,Van R, Pickering LK. Intermediate resistance of Streptococcus pneumoniae to penicillin in children in daycare centers. Pediatr Infect Dis J 1992;11:831.

16. Reichler MR,Allphin AA, Breiman RF,Schreiber JR,Arnold JE, MCD oug LK et al The spread of multiply resistant Streptococcus pneumoniae at a $D$ ay $C$ are $C$ enter in 0 hio. I Infect D is 1992;166:1346.

17. Boken DJ, C hartrand SA, Goering RV, Kruger R, Harrison CJ.C olonization with penicillin-resistant Streptococcus pneumoniae in a child-care center. Pediatr Infect D is J 1995;14:879.
18. Zenni MK, Cheatham SH, Thompson JM, Reed GW, Batson AB, Palmer PS et al. Streptococcus pneumoniae colonization in the young child: Association with otitis media and resistance to penicillin. J Pediatr 1995;127:533.

19. Homoe P, Prag J, Farholt S, Henrichsen J, Hornsleth A, Killian M et al. High rate of nasopharyngeal carriage of potential pathogens among children in G reenland: Results of a clinical survey of middle-ear disease. Clin Infect $D$ is 1996:23:1081.

20. Fairchok MP, A shton W S, Fischer GW. Carriage of penicillin-resistant pneumococci in a military population in W ashington, D.C : Risk factors and correlation with clinical isolates. C lin Infect D is 1996;22:966.

21. Chiou CC, LiuY, HuangT, H wangW K,W ang JH, Lin HH et al. Extremely high prevalence of naso pharyngeal carriage of penicillin-resistant Streptococcus pneumoniae among children in Kaohsiung,Taiwan.J C lin Microbiol 1998:36:1933.

22. Ruoff KL. Streptococci. En: Murray RR, Baron EJ, Pfaller MA, Tenover FC, Yolken RH, ed. Manual of Clinical Microbiology. 6th ed. Washington, D.C.:ASM Press, 1995;299.

23. Jacobs MR, G aspar MN, Robins.Browner RM, Koornhof HJ.Antimicrobial susceptibility testing of pneumococci. 2. Determination of optimal disc diffusion test for detection of penicillin $\mathrm{G}$ resistance. J Antimicrob Chemother 1980; 6:53.

24. N ational Committee for Clinical Laboratory Standards. Minimum inhibitory concentrations (MIC) interpretive standards $(\mathrm{mg} / \mathrm{ml})$ for Strepto coccus spp.Villanova (PA): $\mathrm{N}$ ational Committee for Clinical Laboratory Standards, 1997;vol 17, no. 2, M100-S7.

25. D ean A, D ean J, C oulombier D, Smith DC, Brendel KA,Arner TG et al. Epi-Info version 6.04:A word processing, database, and statistics program for epidemiology on microcomputers. Centers for Disease Control and Prevention, Atlanta (GA), 1994.

26. Celedon JC, Litonjua AA, W eiss ST, Gold DR. D ay care attendance in the first year of life and illnesses of the upper respiratory tract in children with familial history of atopy. Pediatrics 1999;104: 495.

27. Loda FA, Collier AM, Glezen W P, Strangert K, Clay W A, Denny FW. $O$ ccurrence of $D$ iplococcus pneumoniae in the upper respiratory tract of children.J Pediatr 1975;87:1087-1093.

28. Ghaffar F, Friedland IR, MCC racken GH. Dynamics of nasopharyngeal colonization by Streptococcus pneumoniae. Pediatr infect D is J 1999;18:638. 29. Dagan R, Melamed R, Muallem M, Piglansky L,Yagupsky P. N asopharyngeal colonization in Southern Israel with antibiotic-resistant pneumococci during the first two years of life: Relation to serotypes likely to be included in pneumococcal conjugate vaccines.J Infect $D$ is 1996;174:1352. 30. Chiou CC, Liu Y, Huang T, H wang W, W ang J, Lin $\mathrm{H}$ et al. Extremely high prevalence of naso pharyngeal carriage of penicillin-resistant Streptococcus pneumoniae among children in Kaohsiung, Taiwan. J Clin Microbiol 1998:36:1933.

31. Gray BM,Turner ME, Dillon HC . Epidemiologic studies of Streptococcus pneumoniae in infants. Am J Epidemiol 1982;116:692.

32. Gray BM, Dillon HC. Clinical and epidemiologic studies of pneumococcal infection in children. Pediatr Infect D is J 1986;5:201.

33. A hman H, Kaythy H, Tamminen P,Vuorela A, Malinoski F, Eskola J. Pentavalent pneumococcal oligosaccharide conjugate vaccine PncCRM is welltolerated and able to induce an antibody response in infants. Pediatr infect Dis J 1996;15:134

34. Rennels M B, Ewards KM, Keyser ling HL, Reisinger KS, Ho german DA, Madore DV. Safety and immunogenicity of heptavalent pneumococcal vaccine conjugated to CR197 in United States infants. Pediatrics 1998;101:604

35. Mbelle N, Huebner RE, W asas AD, Kimura A, Chang I, Klugman KP. Immunogenicity and impact on nasopharyngeal carriage of a nonavalent pneumococcal conjugate vaccine.J Infect D is 1999; 180: 1171. 